National governments, the international community and commercial interests should agree by 2015 on which mechanisms would work best to finance $\sum$ deep-sea protection and restoration, and by 2020 , cooperate on implementing the fund. If we wish to continue to enjoy the benefits of deep-sea ecosystems, it is essential that we find ways to finance deep-sea research, reserves and restoration.

Edward B. Barbier is professor of economics at the University of Wyoming, Laramie. David Moreno-Mateos is at the CNRS Centre of Evolutionary and Functional Ecology, Montpellier, France. Alex D. Rogers is in the Department of Zoology, University of Oxford, UK. James Aronson is at the CNRS Centre of Evolutionary and Functional Ecology, Montpellier, France, and at the Missouri Botanical Garden, St Louis, Missouri.

Linwood Pendleton is senior fellow in the Ocean and Coastal Policy Program, Nicholas Institute for Environmental Policy Solutions, Duke University, Durham, North Carolina. Roberto Danovaro is in the Department of Life and Environmental Sciences, Polytechnic University of Marche, Ancona, Italy, and at the Anton Dohrn Zoological Station, Naples, Italy. Lea-Anne Henry is at the Centre for Marine Biodiversity and Biotechnology, School of Life Sciences, Heriot-Watt University, Edinburgh, UK. Telmo Morato is at the Institute of Marine Research in the Department of Oceanography and Fisheries, University of the Azores, Horta, Portugal, and at the Laboratory for Robotics and Systems in Engineering and Science, Portugal. Jeff Ardron is at the Institute for Advanced Sustainability Studies, Potsdam, Germany. Cindy L. Van Dover is in the Division of Marine Science and Conservation, Nicholas School of the Environment, Duke University, Beaufort, North Carolina. e-mail:ebarbier@uwyo.edu

1. Priede, I. G. et al. ICES J. Mar. Sci. 68, 281-289 (2011).

2. Van Dover, C. L. Nature 470, 31-33 (2011).

3. Van Dover, C. L. et al. Mar. Policy 44, 98-106 (2013).

4. Strömberg, S. M., Lundälv, T. \& Goreau, T. J. J. Exp. Mar. Bio. Ecol. 395, 153-161 (2010).

5. Dahl, M. Conservation genetics of Lophelia pertusa. PhD Thesis, Paper V. Univ. Gothenburg (2013).

6. Jobstvogt, N., Hanley, N., Hynes, S., Kenter, J. \& Witte, U. Ecol. Econ. 97, 10-19 (2014).

7. Wattage, P. et al. Fish. Res. 107, 59-67 (2011).

8. Ressurreição, A. et al. Ecol. Econ. 70, 729-739 (2011).

9. Sumaila, U. R. et al. Mar. Policy 34, 495-497 (2010).

10.Sandrea, R. \& Sandrea, I. Oil Gas J. 108, 48-53 (2010).

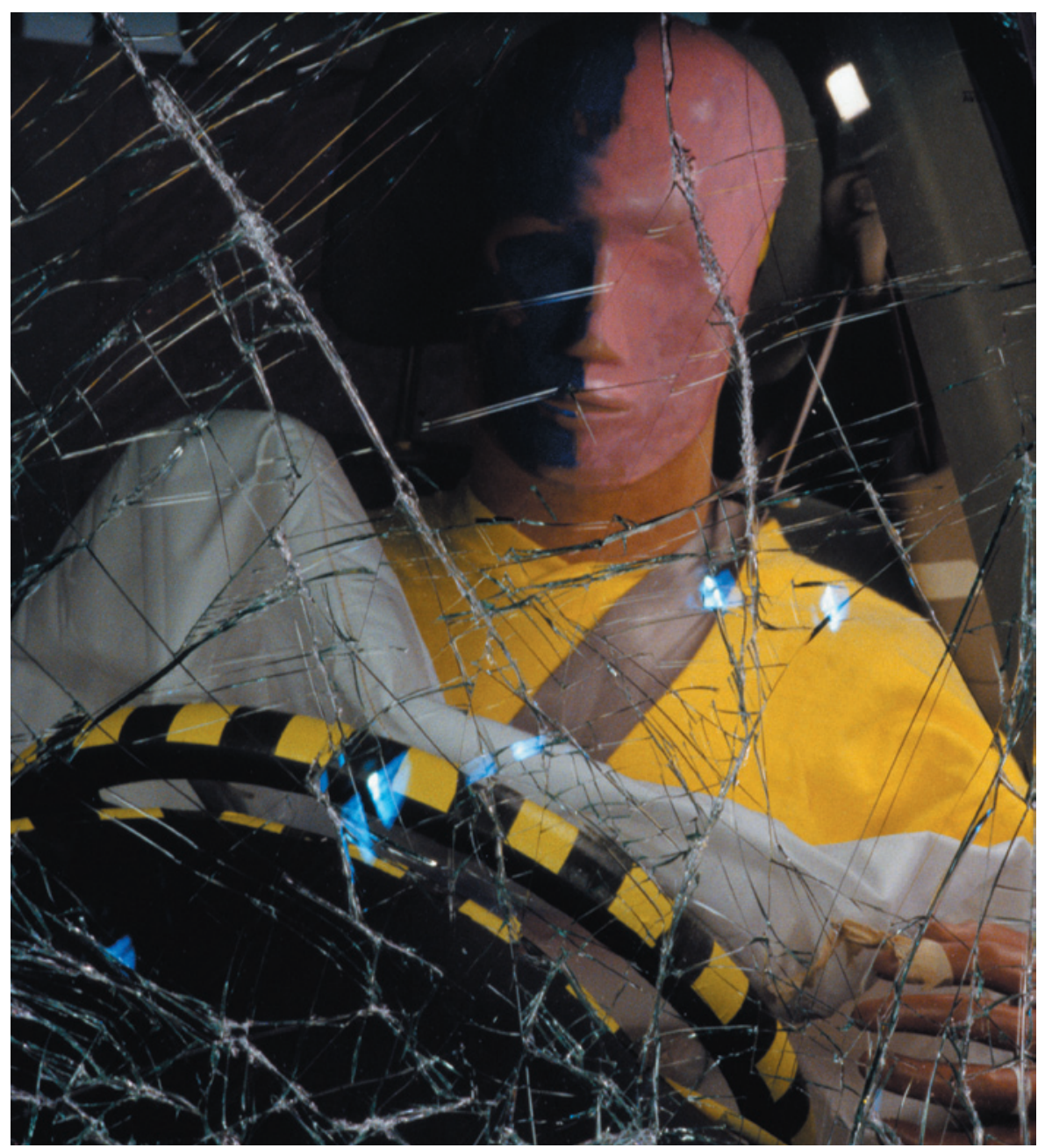

Early airbags were dangerous to women and children, having been designed for adult men.

\title{
Embed social awareness in science curricula
}

\author{
Separate ethics courses are not enough, argues
}

Erin A. Cech. Understanding the public-welfare impacts of science and engineering is a core professional skill.

$\mathrm{A}$ s a social scientist who is also trained as an engineer, I am puzzled by how often public-welfare and socialjustice issues are viewed as irrelevant or tangential to 'real' technical work in science, technology, engineering and mathematics (STEM) professions. I carried out a study ${ }^{1}$, the results of which suggest that university education exacerbates this culture of disengagement.

Between 2003 and 2008, I surveyed a total of more than 300 engineering students in four US universities - a large state college, an elite technical college, a small engineering-only university and a small private liberal-arts college. Following students from their first year to 18 months after their graduation, I found that, on average, they left their degrees less interested in public welfare than when they began.

The reverse should be true. STEM practitioners and educators increasingly recognize that those who understand the role of their profession in society are better at solving real-world problems ${ }^{2}$. Ethics courses for STEM students are proliferating. But adding a few courses is not enough. Social issues should be embedded throughout STEM curricula. Scientists and engineers must view the understanding of the social context 


\section{SOCIAL DISENGAGEMENT}

In a US survey, more than 300 engineering students rated four aspects of the socia relevance of their work lower at the end of their undergraduate degrees than at the start.

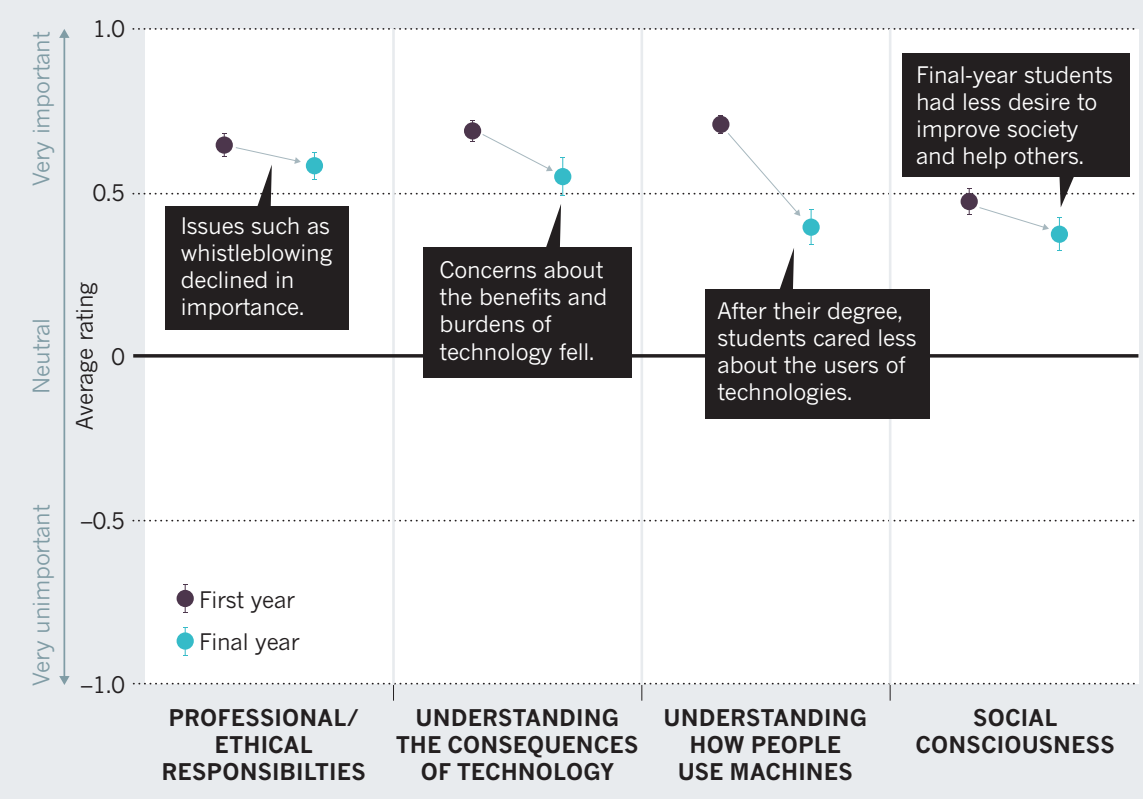

of their work as a core professional skill. This culture of disengagement is a concern because most STEM problems have cultural and political issues built into them ${ }^{3-5}$. The early design of safety airbags in cars, for example, was subject to gender bias. In 1993, the US National Highway Traffic Safety Administration dictated to manufacturers that the rate of force for airbag deployment had to be strong enough to protect an unbelted, average adult male. Car designers did not test their airbags on dummies of the average weight and stature of women or children; injuries and deaths followed ${ }^{6}$.

A graduate student designing technology to read emotion in faces told me another story. On demonstrating the equipment to local school students, he realized that the method of recording changing expressions by reflecting light off faces did not work for people with dark skin. The technology had tested fine for everyone in the lab, but they were all light-skinned. "We didn't think to try it out on others who didn't look like us," he said.

The culture of disengagement also makes it more challenging to achieve equality within STEM. Discussions of power, exclusion, and inequality of women, lesbian, gay, bisexual, transgender and racial- or ethnic-minority individuals are typically seen as tangential best left to diversity workshops and the like. But by standing aloof, we validate the existing power structures and unequal status quo.

My study ${ }^{1}$ examined four attitudes among engineering students: the importance to them of their professional and ethical responsibilities (such as whistleblowing), of understanding the uneven consequences of technologies (such as nuclear technologies and the Internet), of understanding how people use machines, and of the desire to improve society and help others. Although most students rated these issues as 'important' rather than 'unimportant', they weighted them as more neutral in each subsequent year of their degrees (see 'Social disengagement').

The more-neutral "Public-welfare scores lingered or concernsshould worsened between be incorporated graduating and intomarled entering the engihomework neering workforce.

and exam problems."

The findings suggest that this is not a simple tale of 'growing up' and losing naivety. It is clear that the curricular emphasis of engineering programmes had a significant effect on students' public-welfare beliefs. Students in programmes that played down the policy implications of engineering, for example, expressed less personal concern with professional and ethical responsibilities in the surveys.

\section{PUBLIC WELFARE MATTERS}

The diversity of educational approaches represented by these four universities suggests there is a broader problem across engineering education - and perhaps STEM in general. All four institutions require ethics courses and education in non-STEM subjects. Two of the colleges expressed commitments to producing 'well-rounded' engineers. It is not that these schools neglect engagement, but that wider culture instils in students the idea that social issues are not central to engineering.

I argue that the culture of disengagement in STEM is propped up by three ideological pillars. The first is depoliticization, the belief that science and engineering are 'pure' spaces free of political and cultural concerns $^{7}$. Second is a technical-social duality, the assumption that technical knowledge and competencies have more value than social ones ${ }^{8}$. The third pillar is meritocracy, the belief that scientific professions are unbiased, with fair systems of advancement $^{7,9}$. All three of these ideologies need to be challenged in the classroom and beyond.

What must be done? Public-welfare concerns should be incorporated into marked homework and exam problems. Rather than asking students to estimate the volume of an abstract pond, for instance, as one engineering programme does, students could work out the quantity of toxic materials produced by a plastics plant. This could open up discussions about possible effects on the community's water supply, about whether toxin levels were dangerous and, if so, how best to inform the community about potential dangers.

I believe that if even $10 \%$ of homework and exam questions required students to reflect on the social ramifications of research and results, scientists and engineers could reverse the slide into disengagement ${ }^{10}$.

Erin A. Cech is assistant professor of sociology at Rice University, 6100 Main Street, Houston, Texas 77005-1892, USA. e-mail:ecech@rice.edu

1. Cech, E. A. Sci. Technol. Hum. Val. (in the press).

2. Schneider, J. Eng. Stud. 2, 1-4 (2010).

3. Knorr Cetina, K. Epistemic Cultures: How the Sciences Make Knowledge (Harvard Univ. Press, 1999).

4. Barry, B. E. \& Ohland, M. W. Sci. Eng. Ethics 18, 369-392 (2012).

5. Mackenzie, D. Inventing Accuracy: A Historical Sociology of Nuclear Missile Guidance (MIT Press, 1990).

6. Pacelli, L. J. Contemp. Health Law Policy 15, 739-756 (1999).

7. Cech, E. A. In Engineering Education for Social Justice: Critical Explorations and Opportunities (ed. Lucena, J.) 67-84 (Springer, 2013).

8. Faulkner, W. Soc. Stud. Sci. 30, 759-792 (2000).

9. Young, M. The Rise of the Meritocracy (Transaction, 1994).

10.Lucena, J. (ed.) Engineering Education for Social Justice: Critical Explorations and Opportunities (Springer, 2013).

\section{CORRECTION}

Owing to an editing error, the Comment piece by Amy W. Ando in 'The Endangered Species Act at 40' (Nature 504, 369-370; 2013) wrongly stated that the ESA protected the American bison (Bison bison). The plains bison has never been listed under the act. 